\title{
Microspectroscopic investigation of malignant cells from cell culture and leukemic patients
}

\author{
Mahmoud Huleihel ${ }^{\mathrm{a}, *}$, Ahmad Salman ${ }^{\mathrm{b}}$, Marina Talyshinsky ${ }^{\mathrm{a}}$, Yelena Souprun ${ }^{\mathrm{a}}$ \\ and Vitaly Erukhimovitch ${ }^{\mathrm{a}}$ \\ ${ }^{a}$ The Institute for Applied Biosciences, Ben-Gurion University of the Negev, Beer-Sheva, Israel \\ ${ }^{\mathrm{b}}$ Department of Physics, Ben-Gurion University of the Negev, Beer-Sheva, Israel
}

\begin{abstract}
In the present study we used microscopic Fourier-Transform Infrared spectroscopy (FTIR) to investigate and to detect malignant cells which were transformed in culture by murine sarcoma virus (MuSV) or obtained from human leukemic patients. The advantage of microscopic FTIR spectroscopy over conventional FTIR spectroscopy is that it facilitates inspection of restricted regions of cell culture or the tissue. Our results showed significant and consistent differences between the various tested normal cells (primary cells and cell lines obtained from different origins) and malignant cells either transformed by MuSV or obtained from human leukemic patients. A considerable decrease in carbohydrates and phosphates levels was seen in malignant cells compared to the normal cells. In addition, the peak attributed to the $\mathrm{PO}_{2}^{-}$symmetric stretching mode at $1082 \mathrm{~cm}^{-1}$ in normal cells was shifted significantly to 1087 in malignant cells. Furthermore, treatment of the leukemic patients with appropriate chemotherapy could be detected easily by FTIR spectroscopy; the spectral absorbance of the cells from the treated leukemic patients became very similar to normal lymphocytes. These results in addition to further differences in the shapes of various bands throughout the spectrum strongly support the possibility of developing the FTIR microscopy for the detection and study of malignant cells and probably as indication for successful treatment.
\end{abstract}

\section{Introduction}

Cancer is the leading cause of death in the western world. It is the number one cause of death for women in the United States. The decline in heart disease mortality continues at a present rate, then cancer will soon be the leading cause of death in the United States and many European countries. For the statistics, about third of the population now living in the US will develop some type of cancer. However, early diagnosis and treatment increase the chances of survival and full recovery [1,2].

Despite the improvement in diagnostic techniques, the vast majority of cancers have either advanced or metastasized by the time they are diagnosed [3]. Hence, there is a need to develop novel non-invasive diagnostic methods to detect the malignancy in the earlier stage.

FTIR spectroscopy has been widely applied in biology and medicine. FTIR has expanded our knowledge on the structure, conformation and dynamics of various molecular components of the cell [4]. With the introduction of microscopy in the modern FTIR instrumentation, FTIR analysis of cells and tissues has become a reality. In recent years, there is bubbling interest to apply FTIR as a tool for the diagnosis of cancer. Successful diagnostic studies of lung [5], breast [6], cervical [7] and prostate [8] and colon [9] cancers have been reported.

\footnotetext{
"Corresponding author: Dr. M. Huleihel, The Institutes for Biosciences, Ben-Gurion University of the Negev, P.O. Box 653, Beer-Sheva 84105, Israel. Tel.: +972 8 6461999; Fax: +972 8 6472970; E-mail: mahmoudh@bgumail.bgu.ac.il.
} 
In the present study we examined the FTIR spectra of cells obtained from various origins before and after malignant transformation. Our results showed significant and consistent differences between normal and malignant cells regardless to their origin.

\section{Materials and methods}

\subsection{Cells and viruses}

Primary cells were obtained from various organs of different animals as follows: Mouse primary fibroblast (MF) and primary kidney (MK) cells were obtained from the bone marrow and kidneys, respectively, of newborn mice. Rat primary fibroblast (RF) and primary lung (RL) cells were obtained from the bone marrow and lungs, respectively, of newborn rats. Rabbit primary fibroblast (RaF) cells were obtained from the bone marrow of rabbits. Human fibroblast (HF) cells were isolated from the foreskins of newborn infants. NIH/3T3 cells, a mouse fibroblast line, and Hep-2 cells, a human cell line, were obtained from the American Type Culture Collection (ATCC), Rockville, MD, USA.

All malignant cells (marked as MFT and HKT, etc.) were obtained by infection of the cells with MuSV. Human lymphocytes (HL) and human leukemic cells (HLT) were isolated from normal and leukemic patients.

Cells were grown in Dulbecco's modified Eagle's medium (DMEM) containing 10\% fetal calf serum (FCS), $1 \%$ glutamine, $50 \mathrm{U} / \mathrm{ml}$ penicillin, $50 \mu \mathrm{g} / \mathrm{ml}$ streptomycin and incubated at $37^{\circ} \mathrm{C}$ in a humidified air containing $5 \% \mathrm{CO}_{2}$.

Clone 124 of TB cells chronically releasing Moloney MuSV-124 [10] was used to prepare the appropriate virus stock.

\subsection{Cell proliferation}

Cells, seeded at a concentration of $0.6 \times 10^{6}$ cells per $9.6 \mathrm{~cm}^{2}$ plate, were incubated for five days at $37^{\circ} \mathrm{C}$ in RPMI medium supplemented with $10 \%$ newborn calf serum (NBCS) and the antibiotics penicillin, streptomycin and neomycin. Each day, the cells were examined for morphological changes, and the number of cells was counted with a hemacytometer.

\subsection{Cell infection and determination of cell transformation}

A monolayer of cells grown in $9-\mathrm{cm}^{2}$ tissue culture plate was treated with $8 \mu \mathrm{g} / \mathrm{ml}$ of polybrene (a cationic polymer required for neutralizing the negative charge of the cell membrane) for $24 \mathrm{~h}$ before infection with the virus. Excess polybrene was then removed, and the cells were incubated at $37^{\circ} \mathrm{C}$ for $2 \mathrm{~h}$ with the infecting virus (MuSV-124) at various concentrations in RPMI medium containing $2 \%$ of NBCS. The unabsorbed virus particles were removed, fresh medium containing $2 \%$ NBCS was added, and the monolayers were incubated at $37^{\circ} \mathrm{C}$. After 2-3 days, the cell cultures were examined for the appearance of malignant transformed cells.

\subsection{Soft agar assay}

A mixture of $25 \%$ of $2 \%$ Bacto agar, $25 \%$ of RPMI $\times 2$ (concentrated medium), $20 \%$ of NBCS and $30 \%$ of RPMI was prepared, and $4 \mathrm{ml}$ of this mixture was poured into a number of $50-\mathrm{mm}$ petri dishes. 
The mixture was left to polymerize at room temperature for about $30 \mathrm{~min}$. This procedure gave a solid agar $(0.5 \%)$ layer. Onto each solid layer was poured $1 \mathrm{ml}$ of $0.36 \%$ agar containing the test cells. This upper layer was prepared by mixing of $18 \%$ of $2 \%$ Bacto agar, $18 \%$ of RPMI $2,20 \%$ of NBCS and $44 \%$ of RPMI. About $10^{5}$ cells were added to each plate. The plates were left at room temperature for about $20 \mathrm{~min}$ and then incubated at $37^{\circ} \mathrm{C}$ in humidified air containing $5 \% \mathrm{CO}_{2}$ for about 14 days. At the end of the incubation period, colonies of transformed cells were counted under a light microscope.

\subsection{Preparation of slides}

Since ordinary glass slides exhibit strong absorption in the wavelength range of interest to us, we used zinc sellenide crystals, which are highly transparent to IR radiation. Normal cells from passage 3-5 or transformed cells (from a fully transformed cell culture) were washed twice with saline and picked up from the tissue culture plates after treatment with trypsin $(0.25 \%)$ for $1 \mathrm{~min}$. The cells were pelted by centrifugation at $1000 \mathrm{rpm}$ for $5 \mathrm{~min}$. Each pellet was washed twice with saline and resuspended in $100 \mu \mathrm{l}$ of saline. The number of cells was counted with hematocytometer, and all tested samples were pelleted again and resuspended in an appropriate volume of saline to give a concentration of 1000 cells $/ \mu 1$. A drop of $1 \mu \mathrm{l}$ of each sample was placed on a certain area on the sellenide crystal, air dried for $4 \mathrm{~h}$ and examined by FTIR microscopy. The radius of such $1 \mu \mathrm{l}$ drop was about $1 \mathrm{~mm}$.

\subsection{FTIR spectra}

FTIR measurements were performed in transmission mode with a liquid nitrogen-cooled MCT detector of FTIR microscope (Bruker IRScope II) coupled to the FTIR spectrometer (BRUKER EQUINOX model $55 / \mathrm{S}$, OPUS software). The spectra were obtained in the wave number range of $600-4000 \mathrm{~cm}$ in the midIR region. A spectrum was taken as an average of 128 scans to increase the signal to noise ratio, and the spectral resolution was at $4 \mathrm{~cm}^{-1}$. The aperture used in this study was 100 microns, since we found that this aperture gives best ratio signal/noise. At lower apertures the quality of spectra was bad due to high levels of noise. In addition, at apertures lower than $20 \mu \mathrm{m}$, there is a diffraction of IR light. Baseline correction and normalization were performed for all the spectra by OPUS software. Baseline correction was done by rubber band method. For the construction of the baseline the spectrum is divided up in $\mathrm{n}$ ranges of equal size. In each range the minimum $y$-value is determined. The baseline is created by connecting of minima with straight lines. Starting from "below" a rubber band is stretched over this curve. The rubber band is the baseline. The baseline points that don't lie on the rubber band are discarded.

Normalization was done by vector method. The average $y$-value of the spectrum is calculated first. This average value is then subtracted from the spectrum so that the middle of the spectrum is pulled down to $y=0$. The sum of the squares of all $y$-values is then calculated and the spectrum is divided by the square root of this sum. The vector norm of result spectrum is 1 . Peak positions were determined using standard method by OPUS software. For each cell type, the spectrum was taken as the average of five different measurements at various sites of the sample.

Each experiment with each cell type was repeated five times.

It is important to mention that there are no considerable differences in spectra from various sites, standard deviation (SD) didn't exceed 0.005 . 


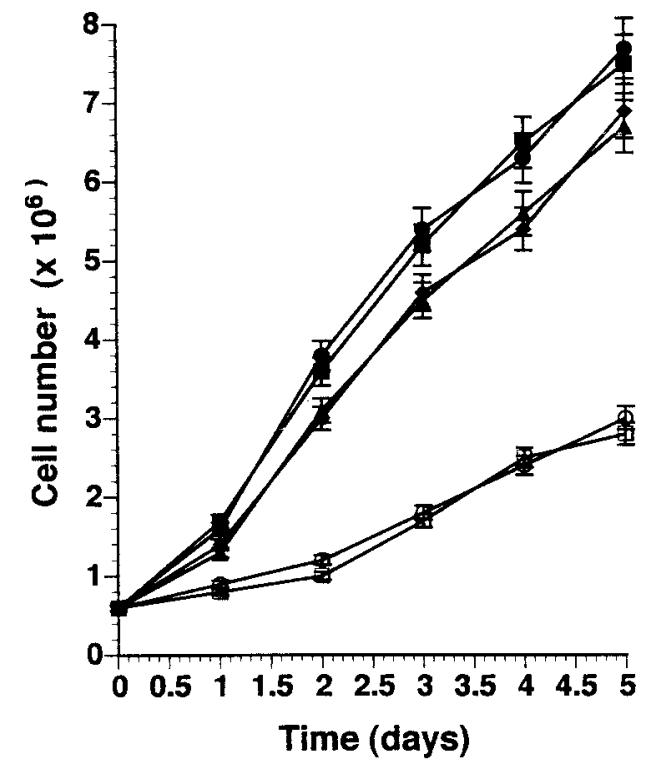

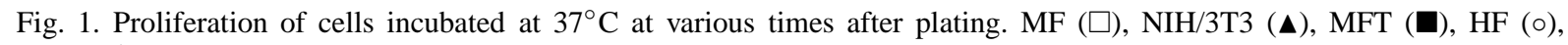
Hep-2 $(\diamond)$ and HFT $(\bullet)$ cells. Data are mean $\pm \operatorname{SD}(n=5)$.

\section{Results and discussion}

\subsection{Cell characteristics}

In the present study various primary cells (1-2 passages in culture), cell lines (thousands of passages in culture) and malignant cells transformed by retroviruses (MuSV) or obtained from leuk were used.

The primary cells differ completely in most of their characteristics and behaviour from malignant cells. Cell lines differ largely in some of their characteristics from primary cells but also differ from malignant cells. Cell lines are very stable in culture compared to primary cells which most of them are dying after several passages (about 20 passages). Primary cells replicate very slowly in culture (Fig. 1) and could not survive high densities: most of them are died after about 10 passages. However up to passages 7-8, the amount of dead cells in these cultures was negligible and did not exceed the normal death rate for cell-line cultures. In contrast, the cell lines replicate rapidly similar to malignant cells (Fig. 1), can reach also much higher densities in cell culture compared to primary cells but they cannot reach that density of malignant cells and cannot produce foci in cell culture, they also cannot grow in soft agar. When $5 \times 10^{6}$ cells were injected subcutaneously to newborn mice, only malignant cells were able to produce tumors 2 weeks after injection (data not shown). Primary cells and cell lines are not able to replicate and produce tumors in new born mice.

\subsection{General IR spectra of the various tested cells}

The spectral absorption of various normal cells (from different origins) and malignant cells transformed in cell culture by a retrovirus (MuSV) or obtained from leukemic patients was examined by FTIR microscopy. Our results showed significant and remarkable differences between normal and malignant cells. In general, the differences between the various normal and malignant cells was evident in gradual increase in the intensities of the absorbance, where the malignant cells are the lowest and the 

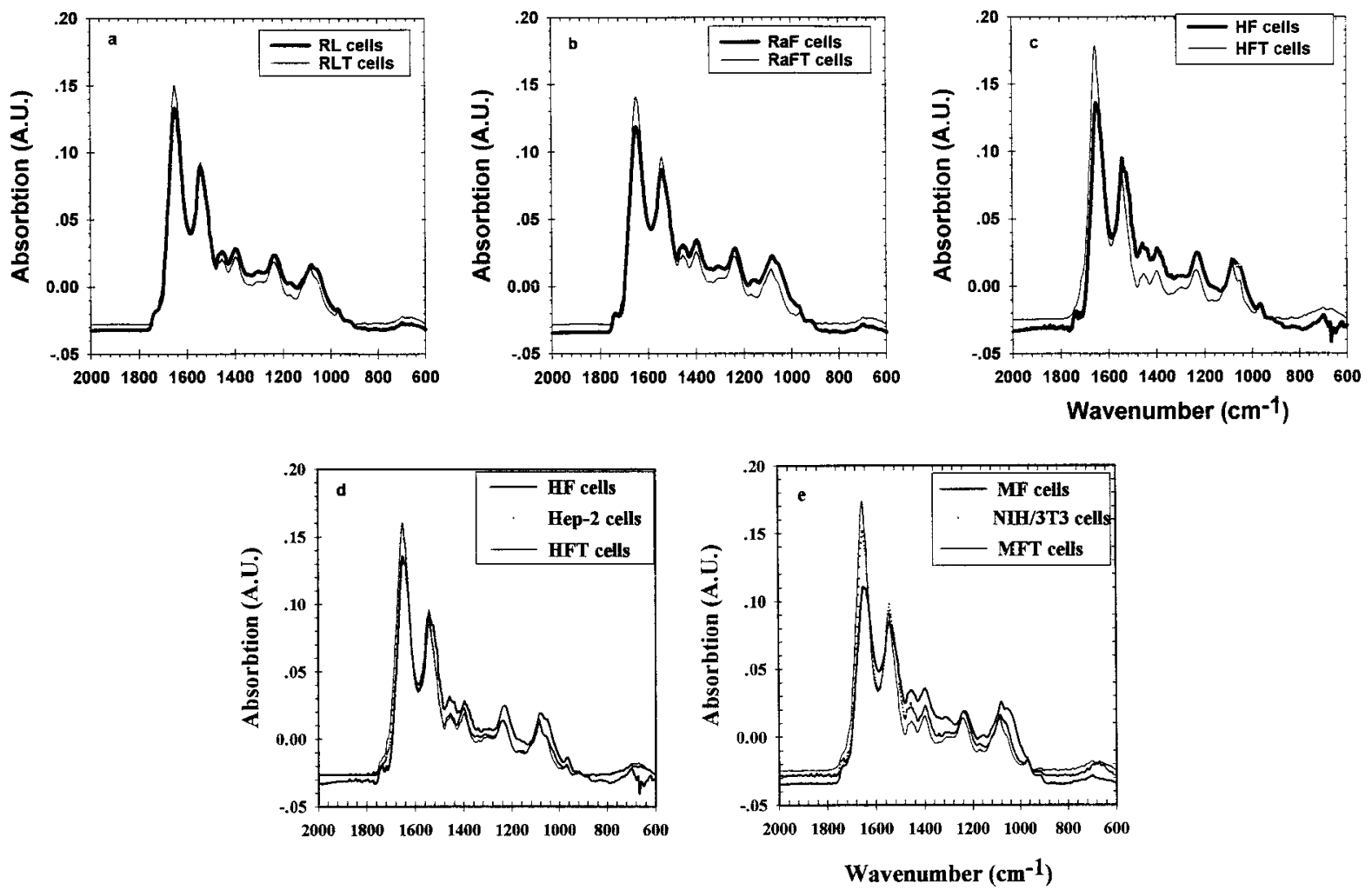

Fig. 2. FTIR microspectroscopy at the region $600-2000 \mathrm{~cm}^{-1}$ of primary cells, cell lines and malignant cells. (Results are means of 5 different and separate experiments for each cell culture.)

primary cells are the highest (Fig. 2). The intensities of absorbance of the cell lines were higher than the malignant cells but lower than the primary cells (Fig. 2). The intensity differences for primary cells, cell lines and malignant cells for amide II were not significant in all tested cases, whereas, significantly higher intensities for amide I were obtained in malignant cells compared to primary cells and cell lines (Fig. 2a,b), although the discrepancy between malignant cells and cell lines was significantly smaller compared to the primary cells. It was reported that the ratio of amide I/II bands could shed light on the change in the DNA content [11]. According to this finding, our results indicate that transformed cells and cell lines had higher DNA absorption and probably, as expected, higher amounts of DNA than the primary cells.

The spectra in the region $1200-1400 \mathrm{~cm}^{-1}$ represent $\mathrm{PO}_{2}^{2}$ asymmetric stretching vibrations [1,12]. Our results showed a significant reduction in the intensity of the absorbance due to these $\mathrm{PO}_{2}^{-}$vibrations for malignant cells compared to normal cells (Fig. 3). In cell lines, as expected, this intensity of absorbance was higher than malignant cells but significantly lower than primary cells. These results are in agreement with previously documented FTIR comparisons of cancerous and normal tissues and cells [1,12-14].

\subsection{Spectra in the 1050-1100 region}

Our measurements show a significant and detectable shift of the peak at $1082-1083 \mathrm{~cm}^{-1}$ (which represent $\mathrm{PO}_{2}^{2}$ symmetric stretching band) for the normal primary cell to $1084 \mathrm{~cm}^{-1}$ in cell lines and 

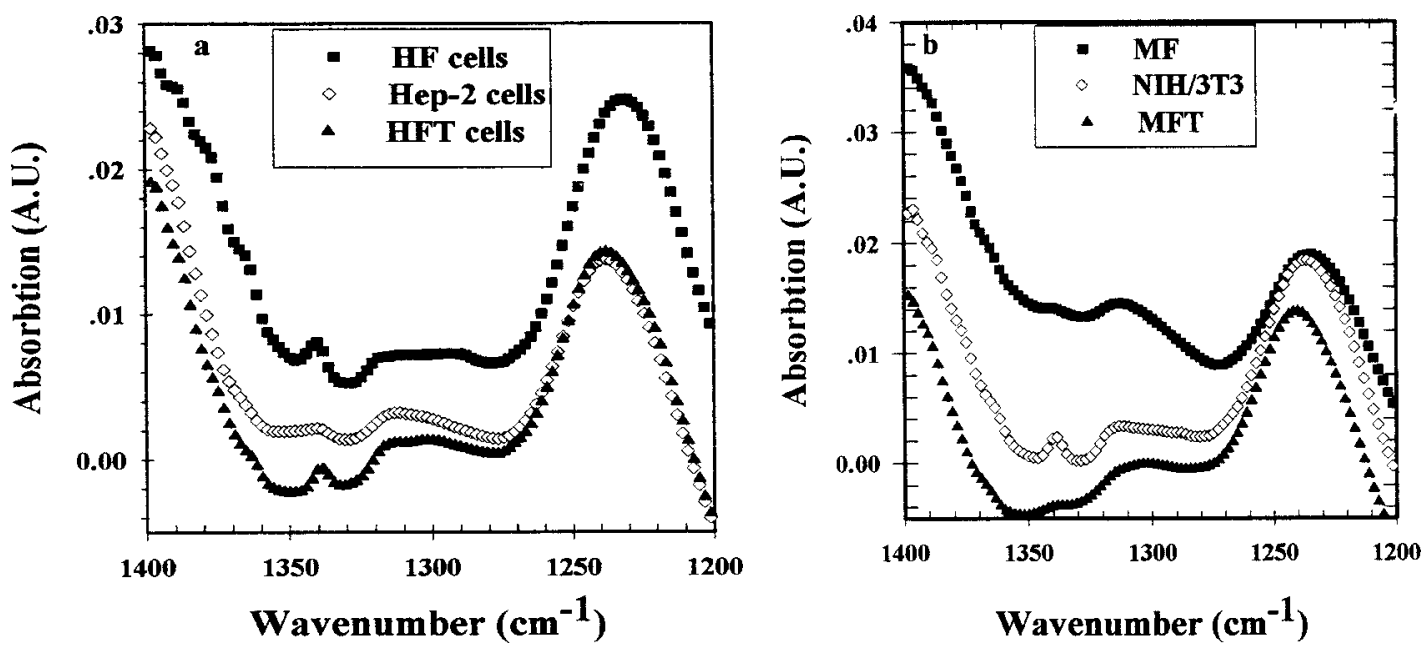

Fig. 3. FTIR microspectroscopy in the region $1200-1400 \mathrm{~cm}^{-1}$ for the tested cells.

Table 1

Peaks in the region $1050-1100 \mathrm{~cm}^{-1}$ in normal primary cells, cell lines and malignant cells

\begin{tabular}{lcc}
\hline Cells & $\begin{array}{c}\text { Position of peak at } \\
\text { (in the } 1050-1100 \mathrm{~cm}^{-1} \text { region) }\end{array}$ & $\begin{array}{c}\bullet \\
\left(\mathrm{cm}^{-1}\right)\end{array}$ \\
\hline MF & 1080.6 & 4 \\
NIH/3T3 & 1084.6 & 7.2 \\
MFT & 1087.2 & \\
MK & 1082.8 & 3.2 \\
MKT & 1086 & \\
RF & 1083.6 & 2 \\
RFT & 1085.6 & \\
RL & 1083.2 & 2.5 \\
RLT & 1085.7 & \\
RaF & 1082.7 & 3.3 \\
RaFT & 1086 & \\
HF & 1081.8 & 2.8 \\
Hep-2 & 1084.6 & 5.1 \\
HFT & 1087.3 & \\
\hline
\end{tabular}

Represents the difference between the position of peaks in malignant cell and the corresponding normal cells.

1086-1087 in malignant cells regardless to their origin (Table 1). These results are in correlation with our and other previous studies $[1,12,15]$.

The shift in the peak $1082 \mathrm{~cm}^{-1}$ may indicate that the environment near the $\mathrm{PO}_{2}^{-}$group has undergone a series of alterations during malignancy or that there were changes in the concentrations of some metabolites such as carbohydrates, which could be related to tumor development and/or to the high rate of replication of these cells, i.e., the high rate of DNA synthesis in the malignant cells [16]. 


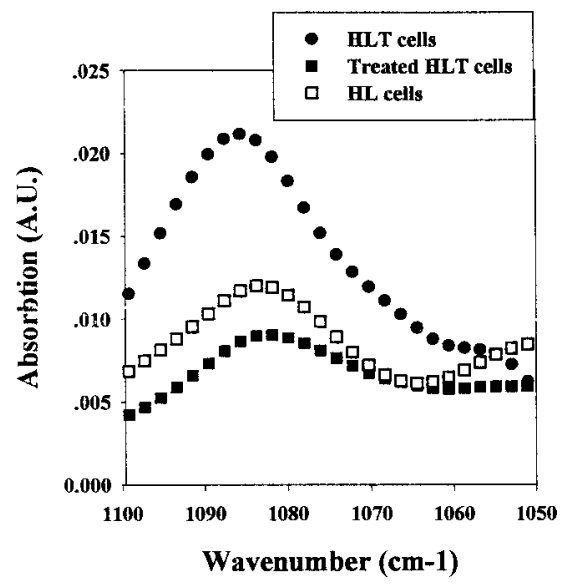

Fig. 4. FTIR microspectroscopy in the region $1050-1100 \mathrm{~cm}^{-1}$ for leukemic cells before and after chemotherapy treatment.

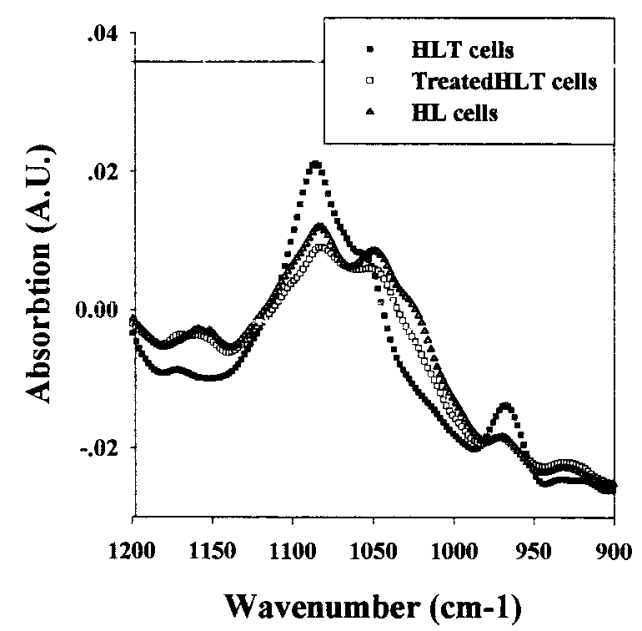

Fig. 5. FTIR microspectroscopy in the region $1200-1400 \mathrm{~cm}^{-1}$ for leukemic cells before and after chemotherapy treatment.

\subsection{Spectral behaviour of leukemic cells treated with chemotherapy}

Lymphocytes were isolated from leukemic patients before and after a course of chemotherapy treatment (1 week of treatment) and their spectral behaviour was examined by FTIR-microscopy. Our results show that lymphocytes from leukemic patients became very similar to normal lymphocytes in their IR spectra as can be seen in Figs 4 and 5. The results presented in Fig. 4 show that the position of the $\mathrm{PO}_{2}^{2}$ symmetric stretching band in the treated leukemic cells goes to the direction of it's position in normal lymphocytes. In addition, Fig. 5 shows that carbohydrates peaks levels at 1023 and $1156 \mathrm{~cm}^{-1}$ in leukemic cells reduced significantly compared to normal lymphocytes, while in treated leukemic cells their levels became back similar to normal lymphocytes.

These results prove that FTIR spectroscopy is a sensitive assay for detecting changes resulted from the transformation of cells from normal to malignant or the opposite. This assay might be usable also for follow up of the effectivity of treatments used against cancer cells. 
In conclusion, it seems that the potential of FTIR microscopy as an advanced method for the diagnosis and study of malignant cells transformed is promising.

\section{References}

[1] R.K. Dukor, Vibrational spectroscopy in the detection of cancer, in: Handbook of Vibrational Spectroscopy, J.M. Chalmers and P.R. Griffiths, eds, John Wiley and Sons, 2001, pp. 3335-3360.

[2] L.A.G. Ries, C.L. Kosary, B.F. Hankey, B.A. Miller, L. Clegg and B.K. Edwards, Seer Cancer Statistics Review, National Cancer Institute, Bethesda, 1999, pp. 1973-1996.

[3] T. Burmeister, Rev. Med. Virol. 11 (2001), 369-380.

[4] H. Mantsch and D. Chapman, Infrared Spectroscopy of Biomolecules, John Wiley, NY, 1996, Chap. 2, 6-9.

[5] H.P. Wang, H.C. Wang and Y.J. Huang, Sci. Total Environ. 204 (1997), 283-287.

[6] T. Gao, J. Feng and Y. Ci, Anal. Cell. Pathol. 18 (1999), 87-93.

[7] B. Rigas, K. LaGuardia, L. Qiao, P.S. Bhandare, T. Caputo and M.A. Cohenford, J. Lab. Clin. Med. 35 (2000), $26-31$.

[8] D.C. Malins, N.L. Polissar and S.J. Gunselman, Proc. Natl. Acad. Sci. USA 94 (1997), 259-264.

[9] A. Salman, S. Argov, R. Jagannathan, J. Goldstein, I. Sinelnikov, H. Guterman and S., Cell. Mol. Biol. (Nosiy-le-grand) 47 (2001), OL159-OL166.

[10] J.K. Ball, J.A. McCarter and S.M. Sunderland, Virology 56 (1973), 268-284.

[11] E. Benedetti, E. Bramanti, F. Papineschi and I. Rossi, Appl. Spectrosc. 51 (1997), 792-797.

[12] D. Yang, D. Castro, I. El-Sayed, M. El-Sayed, R. Saxton and Y. Nancy, SPIE 2389 (1995), 543-550.

[13] R. Jagannathan, A. Salman, N. Grossman, Z. Hammody, B. Cohen and S. Mordechai, Europ. Biophysics J. 30 (2001), 250-255.

[14] M. Huleihel, A. Salman, V. Erukhimovitch, R. Jagannathan, Z. Hammody and S. Mordechai, 50 (2002), 111-121.

[15] M. Huleihel, M. Talyshinsky and V. Erukhimovitch, Spectroscopy 15 (2001), 57-64.

[16] H. Susi, in: Structure and Stability of Biological Macromolecules, S.N. Timashett and C.D. Fasman, eds, Marcel Dekker, New York, 1969, pp. 641-653. 


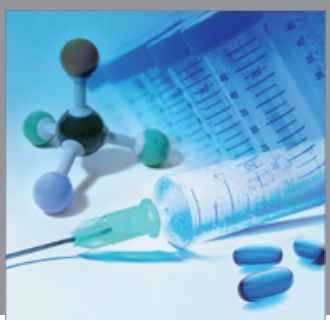

International Journal of

Medicinal Chemistry

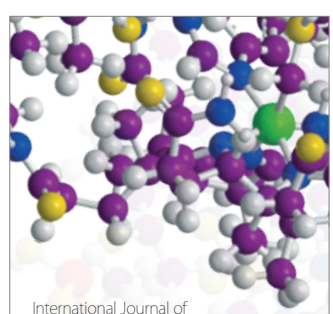

Carbohydrate Chemistry

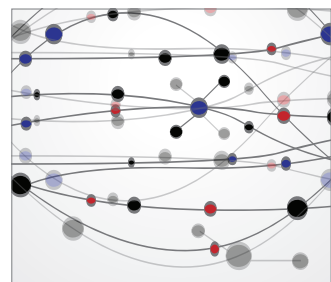

The Scientific World Journal
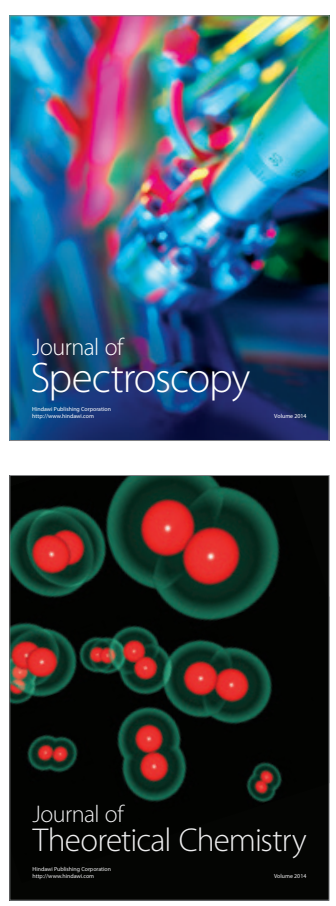
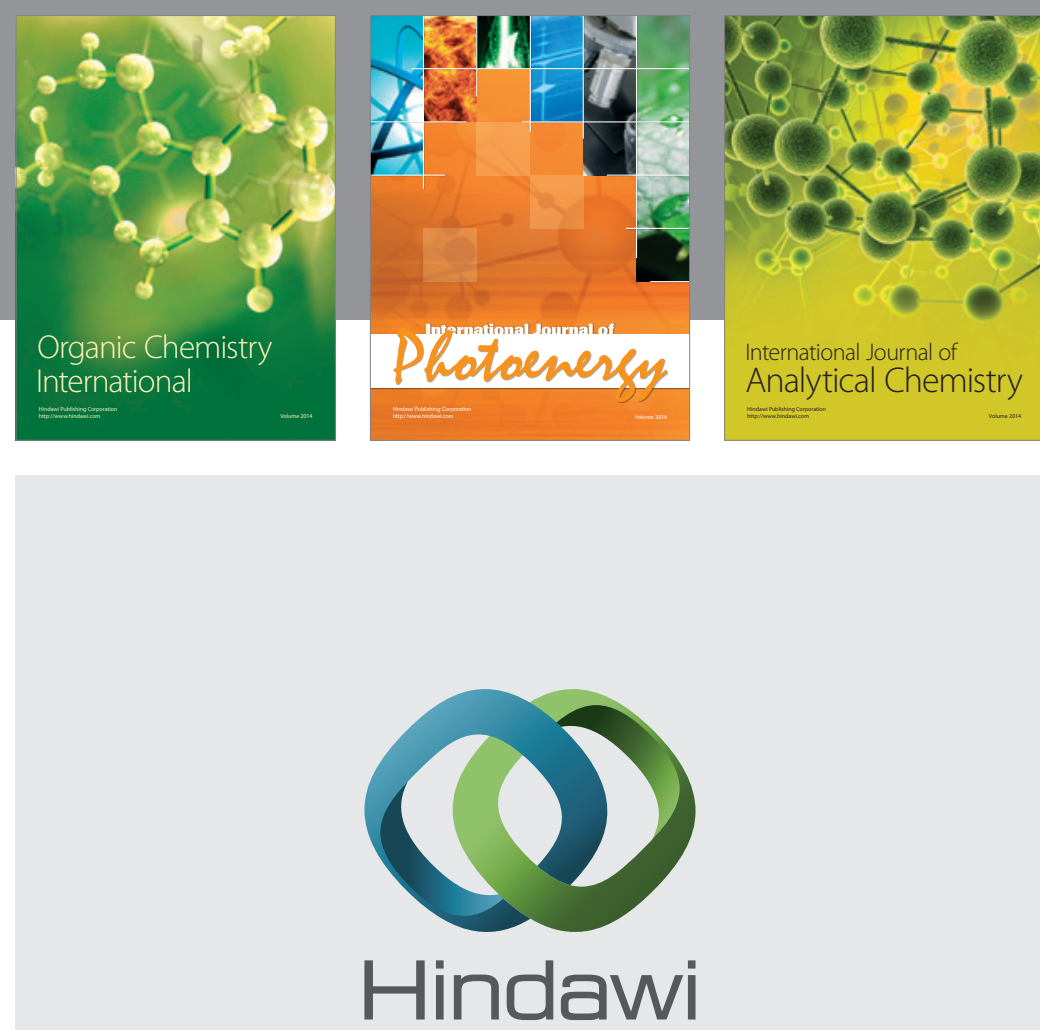

Submit your manuscripts at

http://www.hindawi.com
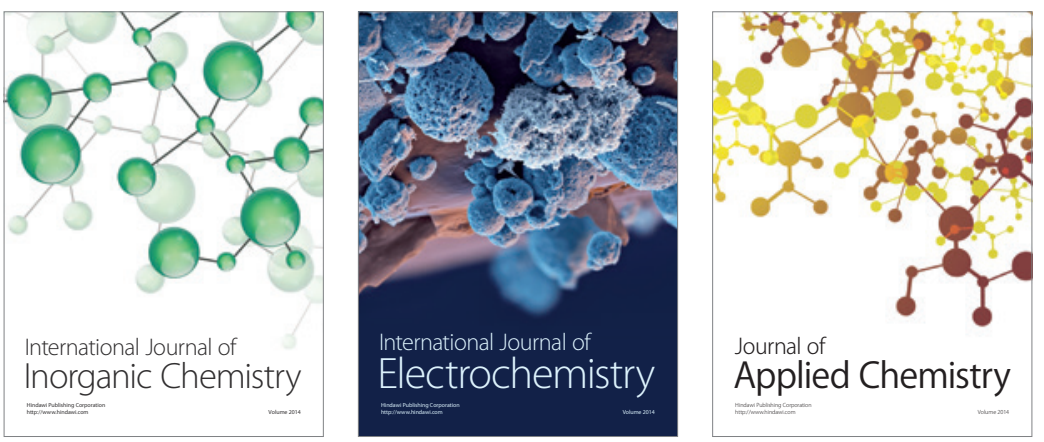

Journal of

Applied Chemistry
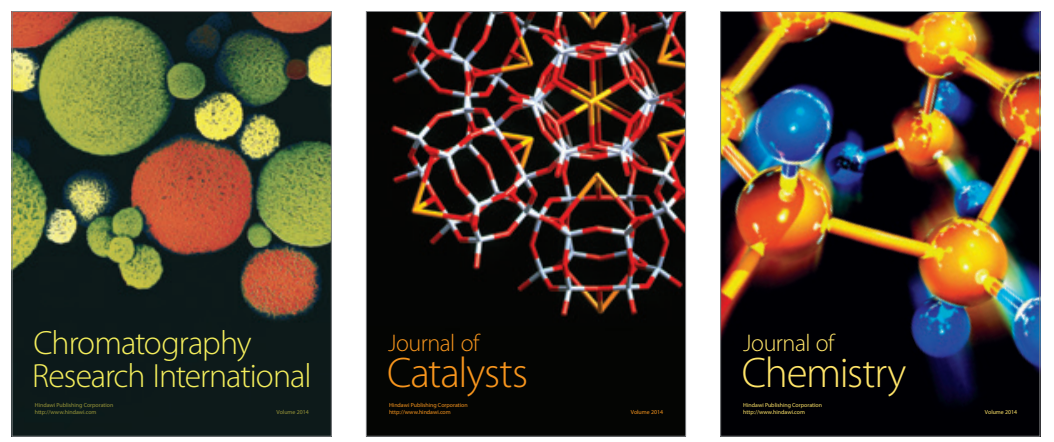
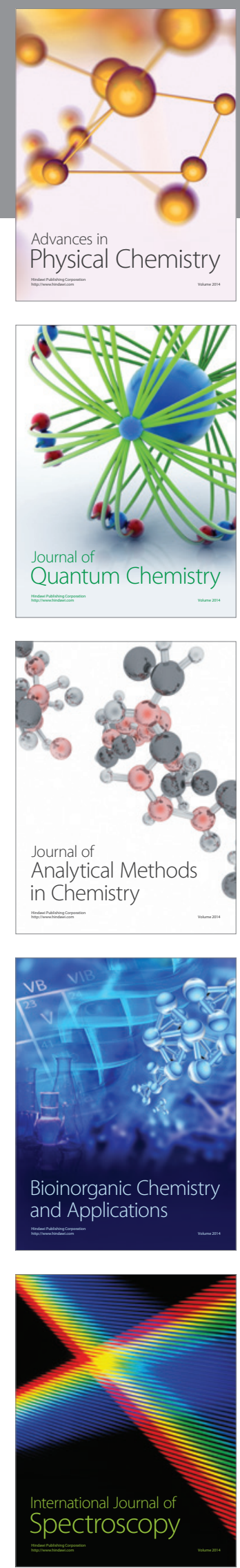